\title{
Associations between continuous measures of disease activity in adult $R A$ and the pediatric ACR response measures: a secondary analysis of JIA data S Ringold ${ }^{2}$, Y Chon ${ }^{3}$ and NG Singer*1
}

\author{
Address: ${ }^{1}$ University Hospitals/Case Medical Center and Rainbow Babies and Children's Hospital, Cleveland, OH, USA, ${ }^{2} \mathrm{Children's} \mathrm{Hospital} \mathrm{\&}$ \\ Regional Medical Center/University of Washington, Seattle, WA, USA and ${ }^{3}$ Amgen, Inc, Thousand Oaks, CA, USA \\ * Corresponding author
}

\author{
from 15th Paediatric Rheumatology European Society (PreS) Congress \\ London, UK. 14-17 September 2008 \\ Published: 15 September 2008 \\ Pediatric Rheumatology 2008, 6(SuppI I):PI2I doi:10.II86/I546-0096-6-SI-PI2I
}

This abstract is available from: http://www.ped-rheum.com/content/6/SI/PI2I

(c) 2008 Ringold et al; licensee BioMed Central Ltd.

\section{Objectives}

To measure correlations between the DAS, DAS28, Simplified Disease Activity Index [SDAI], and Clinical Disease Activity Index [CDAI]) and ACR responses; to determine validity of these measures in polyarticular-course juvenile idiopathic arthritis (polyJIA).

\section{Methods}

Retrospective analysis of 2 etanercept trials. Disease activity was calculated at baseline, $3 \mathrm{mo}$, and $6 \mathrm{mo}$. Data were analyzed independent of treatment arm. Visits were classified by highest level of pediatric ACR response. EULAR response levels were based on DAS/DAS28 values. Correlation coefficients were calculated between the above measures. Areas under the receiver operating characteristic curve assessed discriminative characteristics of each continuous measure to the pediatric ACR response measures.

\section{Results}

Mean DAS, DAS28, CDAI, and SDAI were 3.7, 4.7, 30.8, and 36.4 respectively at baseline, corresponding to high disease activity levels for the DAS, CDAI and SDAI, and moderate for the DAS28. At $3 \mathrm{mo}$, mean values corresponded to low disease activity for the DAS/DAS28, and moderate for the CDAI/SDAI. At $6 \mathrm{mo}$, mean scores corresponded to low disease activity for the DAS/DAS28/CDAI, and moderate for the SDAI. Good EULAR response was seen at 3 and 6 mo. Correlation between the continuous outcome measures and the pediatric core set components was moderate to very good, with the closest correlation observed between the active joint count (kappa $=0.62-$ 0.97).

\section{Conclusion}

Good correlation was seen between the DAS, DAS28, CDAI, and SDAI and the ACR pediatric measures of response, supporting value for prospective validation in polyJIA.

\section{Acknowledgements}

Statistical support by Immunex (a wholly owned subsidiary of Amgen) and Wyeth. 